Check for updates

Cite this: RSC Adv., 2017, 7, 55206

Received 16th September 2017 Accepted 16th November 2017

DOI: 10.1039/c7ra10289e

rsc.li/rsc-advances

\section{Efficient synthesis of butyl levulinate from furfuryl alcohol over ordered mesoporous Ti-KIT-6 catalysts for green chemistry applications $\dagger$}

\author{
Jimmy Nelson Appaturi, (DD *a Mohd Rafie Johan, ${ }^{a}$ R. Jothi Ramalingam, (D) ${ }^{b}$ \\ Hamad A. Al-Lohedan ${ }^{b}$ and J. Judith Vijaya*c
}

\begin{abstract}
Here we describe the synthesis of butyl levulinate by alcoholysis of furfuryl alcohol with $n$-butanol over a series of titanium incorporated mesoporous KIT-6 molecular sieve catalysts prepared by a simple solgel treatment. The prepared catalysts were characterized by FT-IR, BET, HR-TEM, XRD, NH $-T P D, I C P-$ AES, and ${ }^{29} \mathrm{Si}$ MAS-NMR techniques. The characterization results confirmed high BET surface areas with a highly ordered porous network and well-ordered arrangements of pores. Effects of various reaction parameters on the alcoholysis reaction, including the type of catalyst, reaction temperature, time, and catalyst amount, were studied. Among the synthesized catalysts, the 100Ti-KIT-6 showed the best activity giving $94 \%$ conversion with $100 \%$ selectivity towards butyl levulinate. To confirm green chemistry aspects, heterogeneity and reusability tests were performed. Reusability experiments showed that titania catalyst could be recycled for five successive cycles without undergoing a large loss in conversion capabilities. Based on leaching and reusability studies, it was found that the green mesoporous 100TiKIT- 6 is the best highly active catalyst and testified that the catalyst was truly heterogeneous.
\end{abstract}

\section{Introduction}

Due to continuous increase of the world population, an expected looming world energy crisis is becoming dominant. Furthermore, the major source of energy to the world i.e., fossil fuels, has harmful effects on the environment as they emit carbon dioxide $\left(\mathrm{CO}_{2}\right)$ into the atmosphere. To mitigate these crises, biomass-derived renewables are considered as major alternative energy sources because of their renewability and self-control of $\mathrm{CO}_{2}$ emissions to the atmosphere by forming a closed carbon cycle. ${ }^{1}$ Another advantage of these is that they take away municipal solid waste from the environment and convert it into valuable oil. ${ }^{2}$ Hence, biomass exhibits an appreciable pattern of becoming the best alternative energy source to the world. ${ }^{3}$

Among biomass types, cellulosic biomass is abundantly available, a renewable alternative energy resource and which is the main source of sugar generation. ${ }^{4}$ These sugars and other derived molecules have great potential to be converted into other chemicals including being converted into commodity

${ }^{a}$ Nanotechnology \& Catalysis Research Centre (NANOCAT), University of Malaya, 50603 Kuala Lumpur, Malaysia. E-mail: jimmynelson@um.edu.my; Fax: +60 37967 6956; Tel: +60 379676959

${ }^{b}$ Surfactant Research Chair, Chemistry Department, College of Science, King Saud University, P. O. Box 2455, Riyadh 11451, Kingdom of Saudi Arabia

${ }^{c}$ Catalysis \& Nanomaterials Research Laboratory, Department of Chemistry, Loyola College, Chennai 600 034, India

$\dagger$ Electronic supplementary information (ESI) available. See DOI: 10.1039/c7ra10289e chemicals. $^{5}$ Among biomass sugar-derived chemicals, alkyl levulinates have gained specific attention due to their unique properties such as high lubricity, flashpoint stability, non-toxic nature, and finer flow properties under cold conditions. ${ }^{4,6}$ These potential characteristics make it one of the important valueadded chemicals especially as fuel additives in transportation fuels. ${ }^{7}$ Furthermore, alkyl levulinates are used to synthesize drug and chemical intermediates, and flavours and fragrances are used in solvent and plasticizer industries. ${ }^{8}$

In general, alkyl levulinates (i.e., butyl levulinate) can be synthesized via direct and indirect routes $^{6}$ as shown in Scheme 1. In the direct synthesises route a carbohydrate (cellulose, hemicellulose, glucose, fructose, sucrose, or inulin)

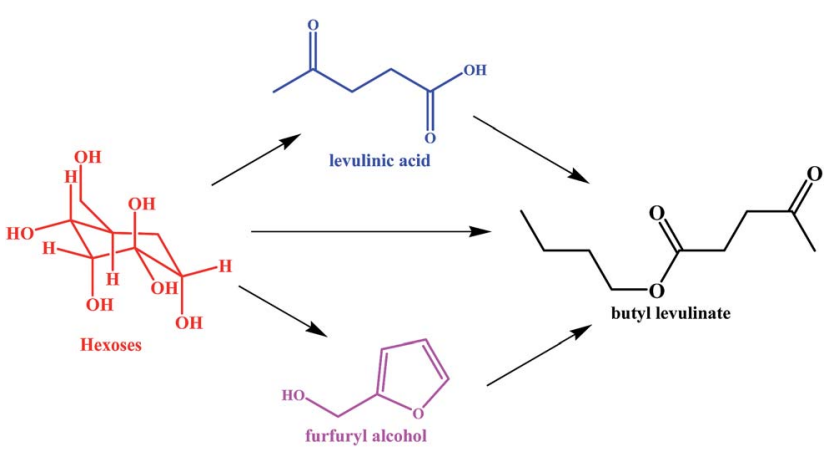

Scheme 1 Direct and indirect routes for the preparation of butyl levulinate from hexoses derived from biomass. 
is converted into alkyl levulinates in the presence of alcohol and acid as a catalyst. Although this route is efficient, time saving, and economical for biomass conversion, it is harmful to the environment and corrosive to instruments. ${ }^{9}$ To improve these drawbacks, two alternative indirect routes to prepare alkyl levulinates were introduced. The first route involves the esterification of levulinic acid with alcohol in the presence of acid catalyst. ${ }^{10} \mathrm{~A}$ second route is alcoholysis of furfuryl alcohol (FAL) by alcohol. ${ }^{11} \mathrm{FAL}$ is more inexpensive than levulinic acid, and an oversupply of FAL and its underutilization in the chemical market makes it a promising molecule to be converted into alkyl levulinates. ${ }^{8}$ The alcoholysis reaction is highly reactive and was carried out using homogenous and/or heterogeneous catalysts.

Conventionally, sulphuric acid, phosphoric acid, and hydrofluoric acid are used in the FAL alcoholysis reaction to prepare alkyl levulinates..$^{12}$ These mineral acids (homogeneous catalysts) are harmful to humans and extremely corrosive to equipment as well as hazardous to the environment. Thus, improving heterogeneous catalysts for FAL alcoholysis has become a very important area of research interest. Heterogeneous acid catalysts, such as an organic inorganic hybrid catalyst containing sulfonic acid immobilized ionic liquids, ${ }^{13}$ a zirconia bifunctionalized organosilica-modified heteropoly acid, ${ }^{14}$ a sulfonic acid-functionalized MIL-101(Cr),${ }^{15}$ and a zincexchanged heteropoly tungstate supported on niobia catalysts, ${ }^{6}$ have been developed recently for production of alkyl levulinates. These above catalysts exhibit good activity and some show excellent performance in FAL alcoholysis. However, most of these catalysts are plagued with difficult recoveries, high cost, and tedious preparation methods.

In recent years, among the various divisions of heterogeneous catalysts, well-ordered mesoporous silica materials have engrossed much attention and also are the most convenient ones since they can be tailor-made to acid or/and basic catalysts. Among ordered mesoporous silica materials, KIT-6 is a remarkable new mesoporous silica with cubic Ia3d symmetry. ${ }^{16}$ The material consists of an interpenetrating bicontinuous network of channels. ${ }^{17}$ The pore structure of KIT-6 is similar to MCM-48; however, it possesses a large pore diameter. The unique 3D network affords a highly opened space with easy and direct access of active sites and reactants to diffuse through the pore channels. ${ }^{18}$ In order to improve the acidity of this material, titanium was incorporated into the KIT- 6 framework via simple sol-gel techniques. In this context, the dispersion of titania over the large surface area of KIT-6 will enhance accessibility of active sites to the reactants and therefore increase their catalytic performances.

To the best of our knowledge this is the first report on the utilization of titania-incorporated KIT- 6 in the absence of sulfonic acid for the synthesis of butyl levulinate via alcoholysis of furfuryl alcohol.

\section{Experimental}

\subsection{Materials}

For the preparation of mesoporous Ti-KIT- 6 catalysts, tetraethylorthosilicate (TEOS, Aldrich, 98\%) and titanium(Iv) isopropoxide (TTIP, Sigma-Aldrich, 97\%) were used as the sources for silicon and titanium, respectively. Poly(ethylene glycol)-block-poly(propylene glycol)-block-poly(ethylene glycol) (Pluronic P123, molecular weight $=5800, \mathrm{EO}_{20} \mathrm{PO}_{70} \mathrm{EO}_{20}$; Aldrich) was used as the structure directing template. Hydrochloric acid (HCl, Friendemann Schmidt, 37\%) and $n$-butanol (Sigma-Aldrich, 99.8\%), as co-solvents, were used in the synthesis process. Deionized water was used throughout the syntheses. $n$-Butanol and furfuryl alcohol (FAL, Aldrich, 98\%) were used for the butanolysis reaction. All other chemicals were used as received without further purification.

\subsection{Preparation of Ti-KIT- 6 catalysts}

The traditional KIT-6 with 3-D-cubic structure was prepared by following the typical synthesis procedure of Wang et al. ${ }^{17}$ The as-synthesized mesostructured Ti-KIT- 6 catalysts with $n_{\mathrm{Si}} / n_{\mathrm{Ti}}$ ratios of $10,20,40,80$, and 100 were synthesized using a following gel composition: 1TEOS : 0.0284$0.284 \mathrm{TTIP}: 0.017 \mathrm{P} 123: 1.93 \mathrm{HCl}: 1.31 n-\mathrm{BuOH}: 195 \mathrm{H}_{2} \mathrm{O}$. In a typical synthesis process, $4.73 \mathrm{~g}$ of $\mathrm{P} 123$ was added to distilled water $(168 \mathrm{~g})$. Then $9.1 \mathrm{~g}$ of concentrated $\mathrm{HCl}$ was added to this solution. After stirring at $35^{\circ} \mathrm{C}$ for $4 \mathrm{~h}$, the template was dissolve in water and $\mathrm{HCl}$ and became homogeneous. Subsequently, $n$ butanol (4.66 g) was added to the clear solution and the stirring continued for $1 \mathrm{~h}$. After one hour of stirring, $10 \mathrm{~g}$ TEOS and $1.36 \mathrm{~g}$ TTIP were added to the solution and the mixture was stirred at $35{ }^{\circ} \mathrm{C}$ for $24 \mathrm{~h}$. The resulting mixture was transferred to a polypropylene bottle and heated at $100{ }^{\circ} \mathrm{C}$ for $24 \mathrm{~h}$ in an oven. The resulting product was filtered hot without washing and dried at $100{ }^{\circ} \mathrm{C}$ for $24 \mathrm{~h}$ in a hot air oven. The dried solid product was crushed to get fine powder and calcined at $540{ }^{\circ} \mathrm{C}$ in air for $24 \mathrm{~h}$ with a heating ramp of $1.5^{\circ} \mathrm{C} \mathrm{min}^{-1}$ in a muffle furnace to eliminate the template. The final material was indicated as 10Ti-KIT-6. The same procedure was adopted for other $x$ Ti-KIT- 6 products, where $x$ denotes $\mathrm{Si} / \mathrm{Ti}$ ratio of the gel.

\subsection{Catalyst characterization}

Fourier transform infrared spectroscopy (FT-IR) was performed using a Bruker IFS66/S. The potassium bromide $(\mathrm{KBr})$ pellet technique was used. Spectra were recorded with a resolution of $\pm 4 \mathrm{~cm}^{-1}$ and scan number of 16 in the range $4000-400 \mathrm{~cm}^{-1}$. Nitrogen adsorption-desorption analysis was performed using a porosimeter (model micromeritics, TriStar II) at $-196{ }^{\circ} \mathrm{C}$ to obtain the Bruner-Emmett-Teller (BET) and Barrett-JoynerHalenda (BJH) parameters. Surface morphology was measured by a high resolution transmission electron microscope (HRTEM) (JEM 2100-F, $200 \mathrm{kV}$ accelerating voltage). Small angle powder X-ray diffraction patterns were recorded on a PANanalytical, X'Pert HighScore diffractometer with primary monochromatic high intensity $\mathrm{CuK}_{\alpha}$ radiation $(\lambda=0.15406$ $\mathrm{nm})$. Ammonia temperature-programmed desorption $\left(\mathrm{NH}_{3}{ }^{-}\right.$ TPD) was conducted on a Thermo Electron TPDRO 1100. Titanium content was determined using inductively coupled plasma atomic emission spectroscopy (ICP-AES) with a Labtum Plasma 8440 instrument. A ${ }^{29} \mathrm{Si}$ MAS-NMR spectrum was recorded using solid state NMR (500 MHz JEOL). 


\subsection{Catalytic activity}

2.4.1. Liquid phase butanolysis of furfuryl alcohol. The butanolysis of furfuryl alcohol was carried out in a $25 \mathrm{~mL}$ roundbottom flask equipped with condenser. In a typical experimental procedure, FAL ( $1 \mathrm{mmol})$ and $n$-butanol $(60 \mathrm{mmol})$ were taken in a round-bottom flask and $0.3 \mathrm{~g}$ of 80 Ti-KIT- 6 was added to the reaction mixture. The reaction was performed at $110{ }^{\circ} \mathrm{C}$ for $5 \mathrm{~h}$; meanwhile, stirring (500 rpm) was applied throughout the reaction. The products were analysed by a GC-FID (Agilent $6890 \mathrm{~N}$ ) equipped with a HP-5 capillary column (30 m length and $0.25 \mathrm{~mm}$ inner diameter). Toluene was used as an internal standard. The products were also identified by GC-MS (Agilent $6890 \mathrm{~N}, \mathrm{DB}-624$ capillary column $60 \mathrm{~m}, 0.32 \mathrm{~mm}$ ) analysis. A series of other synthesized catalysts were used to study the reaction conditions to achieve the highest catalytic performance.

\section{Results and discussion}

\subsection{Characterization of catalysts}

3.1.1. FT-IR. The FT-IR spectra of KIT-6 and 100Ti-KIT-6 are shown in Fig. 1. The broad band around $3426 \mathrm{~cm}^{-1}$ is due to

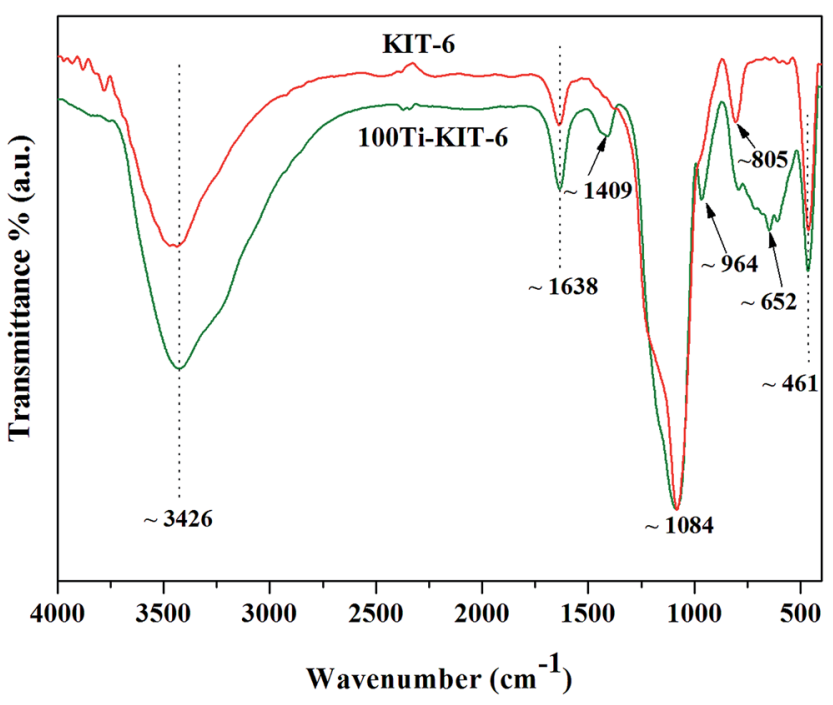

Fig. 1 FT-IR spectra of mesoporous KIT-6 and 100Ti-KIT-6.
$\mathrm{O}-\mathrm{H}$ stretching of $\mathrm{SiO}-\mathrm{H}$ or $\mathrm{TiO}-\mathrm{H}$ and the $\mathrm{HO}-\mathrm{H}$ of water molecules. The intense band at $1084 \mathrm{~cm}^{-1}$ is due to internal and external asymmetric $\mathrm{Si}-\mathrm{O}-\mathrm{Si}$ stretching modes. The bending vibration from $\mathrm{H}_{2} \mathrm{O}$, which was trapped in the silica or titania framework, occurs at $1638 \mathrm{~cm}^{-1}$. The bands at $805 \mathrm{~cm}^{-1}$ and $461 \mathrm{~cm}^{-1}$ are assigned to bending and vibration modes of $\mathrm{Si}-\mathrm{O}-$ $\mathrm{Si}^{19}$ The evidence that titania incorporated into the silica framework can be observed by the FT-IR analysis. The band at $964 \mathrm{~cm}^{-1}$ is due to the stretching vibration of $\mathrm{SiO}_{4}$ units bound in Ti sites (Ti-O-Si). ${ }^{20}$ The band around $1409 \mathrm{~cm}^{-1}$ is assigned to the Ti-O-Ti stretching mode while the broad peak observed at around $550 \mathrm{~cm}^{-1}$ is an indication for the presence of titania. ${ }^{21}$ These results indicate that titania was chemically bonded to the silica support.

3.1.2. $\mathbf{N}_{2}$ adsorption-desorption isotherms. The KIT-6 mesoporous material was incorporated with different amounts of titania. The physicochemical properties of the prepared materials are presented in Table 1 . The BET surface area was obtained in the range of $416-838 \mathrm{~m}^{2} \mathrm{~g}^{-1}$. The gradual reduction in the surface area, pore size, and pore volume with an increase in $\mathrm{Ti}$ content illustrates the successful incorporation of titanium in the pore structure of KIT-6. The $\mathrm{N}_{2}$ adsorption-desorption isotherms for KIT-6 and different $\mathrm{Si} / \mathrm{Ti}$ ratios are shown in Fig. 2. According to the IUPAC classification, all the isotherms designate as type IV with $\mathrm{H} 1$ hysteresis loops. These isotherms and hysteresis loops indicate the characteristic of channel-like pores and narrow pore size distribution. ${ }^{20}$ The presence of uniform meso-pores due to capillary condensation can be seen at high relative pressures $\left(0.6<P / P_{0}<0.8\right)$ for the KIT-6 and the hysteresis loops slightly moved to lower relatives pressures of $\left(0.4<P / P_{0}<0.7\right)$ for the modified mesoporous catalysts.

Pore size distributions of the prepared catalysts were estimated from the $\mathrm{BJH}$ method and the results are depicted in Fig. 3. The formation of large and similar channel-like ordered mesopores is evident by the narrow pore size distribution within a range of $5-10 \mathrm{~nm}$. Pore size distribution is slightly widened with increasing $\mathrm{Si} / \mathrm{Ti}$ ratio. This may be due to blockage of siliceous pores by titanium. These results collaborate well with the pore wall thickness as tabulated in Table 1.

3.1.3. HR-TEM. High resolution transmission electron microscopic images of KIT-6 and 100Ti-KIT-6 are shown in Fig. 4. The HR-TEM images were obtained after the samples

Table 1 The physicochemical properties of the prepared materials

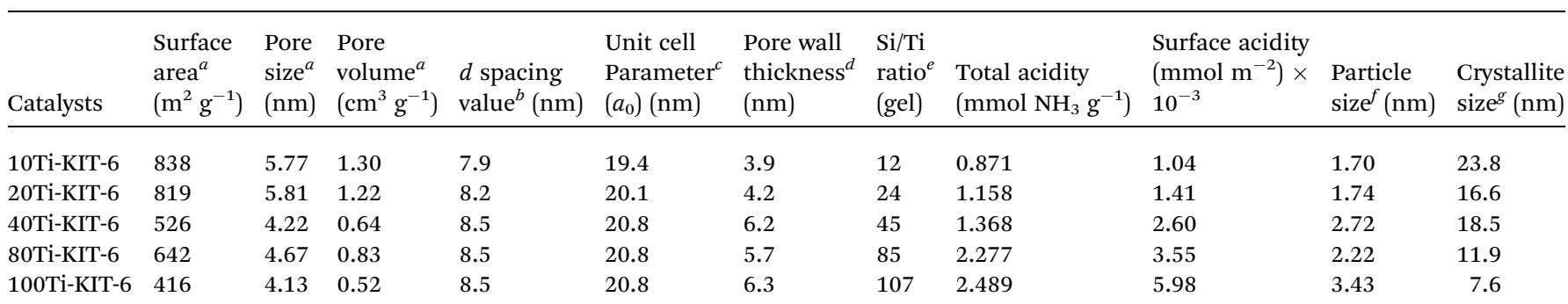

${ }^{a}$ Values obtained from $\mathrm{N}_{2}$ sorption studies. ${ }^{b} d$ spacing value calculated from (211) plane reflection. ${ }^{c}$ Unit cell parameter calculated from the formula $a_{0}=d_{211} \times \sqrt{6} .{ }^{d}$ Pore wall thickness $=a_{0} / 2-$ pore size. ${ }^{e}$ From ICP-AES. ${ }^{f} S_{\mathrm{BET}}$ method. ${ }^{g}$ XRD method using Debye-Scherrer equation. 


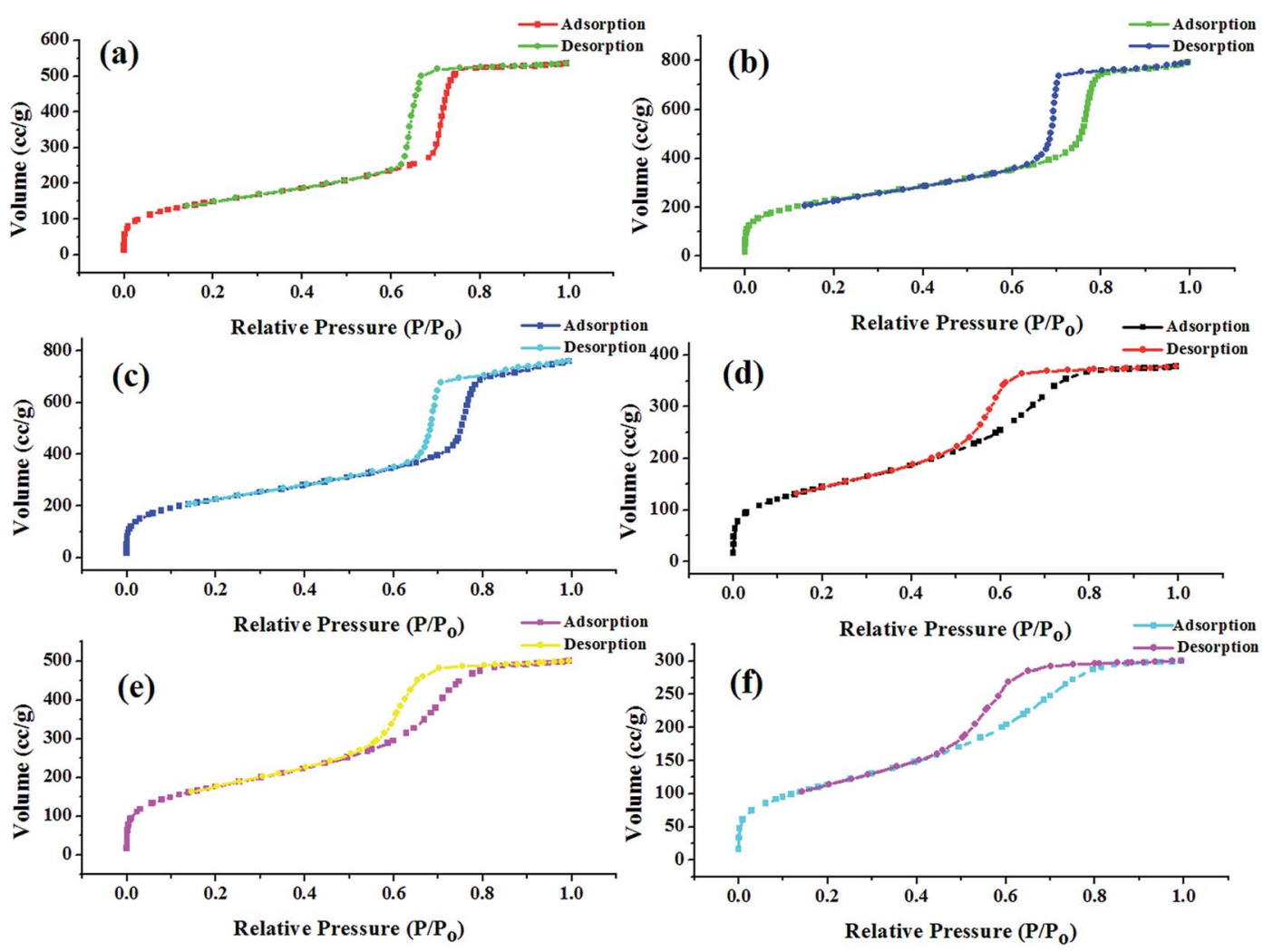

Fig. 2 Nitrogen sorption isotherms for calcined (a) KIT-6 and Ti-KIT-6 with Si/Ti ratios; (b) 10, (c) 20, (d) 40, (e) 80, and (f) 100.

were suspended in ethanol and supported on a copper grid. Both KIT-6 and 100Ti-KIT-6 showed the presence of wellordered cubic mesoporous channels and confirmed that the 100Ti-KIT-6 sample possesses Ia3d cubic structure as does KIT-6.

3.1.4. PXRD. The small angle powder X-ray diffraction patterns of KIT-6 and Ti-KIT- 6 are shown in Fig. 5. The XRD patterns of KIT-6, 10Ti-KIT-6, and 20Ti-KIT-6 catalysts showed a well-resolved intense peak at around 1.1 corresponding to a body-centered Ia3d symmetry with $d_{211}$ space group. This result indicates the catalysts possess a well-ordered pore arrangement. However, in other prepared catalysts, the peak position which is indexed to (211) reflection significantly shifted and do not appear as clear peaks. This phenomenon can be ascribed to the incorporation of a larger amount of titania species into the support. Nevertheless, the slight disappearance of the $h k l(211)$ peaks does not result in the reduction of a longrange order of hexagonally arranged porosity; hence, it appeared in the high resolution transmission electron microscopies study. Unit cell parameters of the catalysts were calculated based on the reflection (211) using the formula, $a_{0}=d_{211}$ $\times \sqrt{6}$ and they are tabulated in Table 1 .

Wide angle powder X-ray diffraction patterns of KIT- 6 and TiKIT- 6 are shown in Fig. S1. $\dagger$ As can be seen from Fig. S1, $\dagger$ KIT-6 possess a very broad peak at around $2 \theta=22^{\circ}$ corresponding to amorphous silica. The amorphous nature of KIT-6 turns into a one after incorporation of titania into the pore structure of the bare catalyst. The data indicate crystallinity increases with an increase of titanium contents. All the prepared catalysts show titania presence in the form of the anatase phase as indicated by the peaks at $2 \theta=25.3^{\circ}(101), 38.1^{\circ}(004), 48.1^{\circ}(200), 54.7^{\circ}(105)$, $55.5^{\circ}(211), 62.8^{\circ}(204), 70.1^{\circ}(220)$, and $75.2^{\circ}(215)$ (JCPDS-ICDD 21-1272). No reflection peak at $27.4^{\circ}(110)$ was observed for any of the samples which indicates the absence of titania in the form of rutile phase. ${ }^{22}$ These findings are similar to those obtained by M. Hussain et al. ${ }^{23}$ The average particle size of the synthesized catalysts was calculated using a BET-specific surface area method assuming that all the particles have the same spherical shape and size. ${ }^{24}$ The average size of crystallites was determined based on the $25^{\circ}$ line in XRD peak broadening using the Debye-Scherrer equation. The results in Table 1 are in fair agreement, but due to high surface area the particle sizes are smaller. But to the contrary, the average particle size calculated by BET is smaller than the crystallite size calculated by XRD. These results are inconsistent because of the formation of aggregates and/or agglomerates of crystals due to the calcination temperature. These results show that the particles contain several crystallites.

3.1.5. $\mathbf{N H}_{3}$-TPD and ICP-AES. Total acidity values for TiKIT-6 samples are given in Table 1. The values are calculated based on the amounts of ammonia desorbed. Based on these results, the total acidity of the catalysts increased with increasing titania loading. We estimate that the surface acidity of titania in 10Ti-KIT-6, 20Ti-KIT-6, 40Ti-KIT-6, 80Ti-KIT-6, and 100Ti-KIT-6 are 1.04, 1.41, 2.60, 3.55, and 5.98 $\left(\times 10^{-3} \mathrm{mmol} \mathrm{m}^{-2}\right)$, respectively. Among all the prepared 

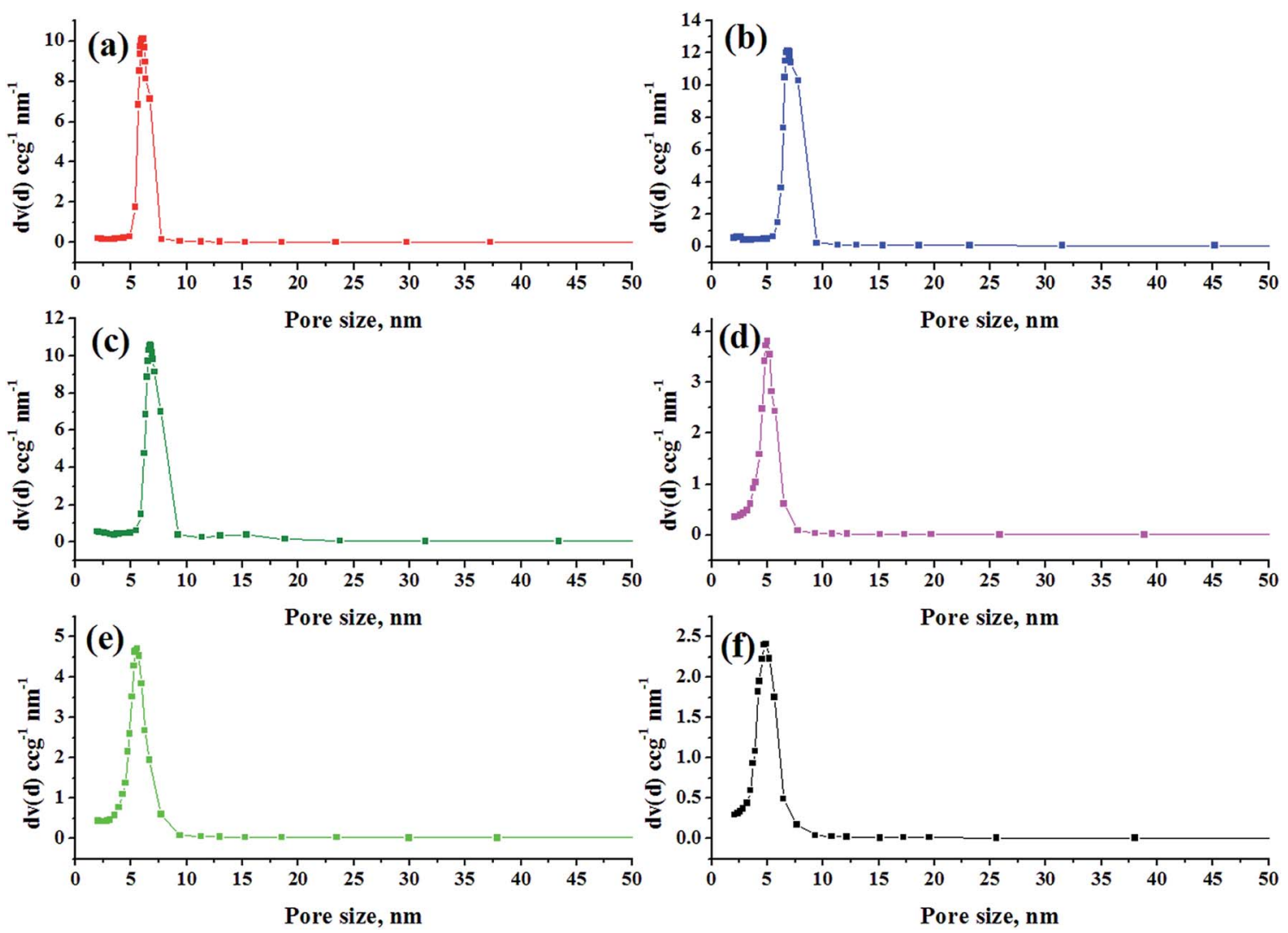

Fig. 3 Pore size distribution for calcined (a) KIT-6 and Ti-KIT-6 with Si/Ti ratios; (b) 10, (c) 20, (d) 40, (e) 80, and (f) 100.

catalysts loading, 100Ti-KIT-6 exhibited the highest amount of surface acidity. The presence of titanium in Ti-KIT- 6 was determined by ICP-AES with the values presented in Table 1 . The results indicate a higher $\mathrm{Si} / \mathrm{Ti}$ ratio than the gel composition. Under neutral condition, the hydrolysis of titanium alkoxide occurred nearly instantaneously while the hydrolysis of the silicon precursor was much slower. The decrease of the hydrolysis rate of a titanium precursor to match the hydrolysis rate of the silicon occurred at the low acidity level. This process may improve the interaction between $\mathrm{Ti}-\mathrm{OH}$ and $\mathrm{Si}-\mathrm{OH}$ species in the prepared gel and resulting in the $\mathrm{Si} / \mathrm{Ti}$ ratios of the prepared materials being very close to that of the gel. A similar trend was observed by L. Kumaresan et al. ${ }^{20}$
3.1.6. ${ }^{29} \mathrm{Si}$ MAS-NMR. The ${ }^{29} \mathrm{Si}$ MAS-NMR of KIT-6 and 100Ti-KIT- 6 were carried out and the results are included under the ESI data (Fig. S2 and S3 $†$ ). KIT-6 showed distinctive peaks at $-90.36,-99.64$, and $-100.64 \mathrm{ppm}$ corresponding to $\mathrm{Q}^{2}\left(\mathrm{Si}(\mathrm{OSi})_{2}(\mathrm{OH})_{2}\right), \mathrm{Q}^{3}\left(\mathrm{Si}(\mathrm{OSi})_{3}(\mathrm{OH})\right)$, and $\mathrm{Q}^{4}\left(\mathrm{Si}(\mathrm{OSi})_{4}\right)$ silicon atoms, respectively. However, in 100Ti-KIT-6 the chemical shift for the $\mathrm{Q}^{2}$ and $\mathrm{Q}^{3}$ were shifted slightly down field and the $\mathrm{Q}^{4}$ peak disappeared compared to KIT-6. In addition, the results show that the relative signal intensity ratio of 100Ti-KIT-6 is much lower than that of KIT-6. These observations clearly confirmed the stabilization of the active titanium species by the $\mathrm{Si}-\mathrm{OH}$ groups, with huge amounts of $\mathrm{Si}-\mathrm{O}-\mathrm{Ti}$ formation. A similar change was observed by Selvaraj et al. ${ }^{25}$
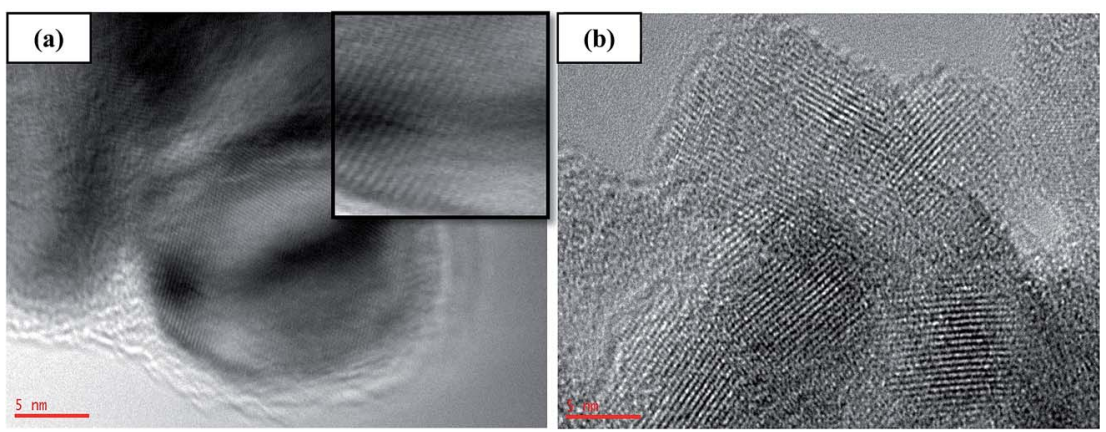

Fig. 4 The HRTEM micrographs of (a) KIT-6 and (b) 100Ti-KIT-6 viewed perpendicular to the channel axis (110) plane. The inset shows expansion of the KIT- 6 mesostructure. 

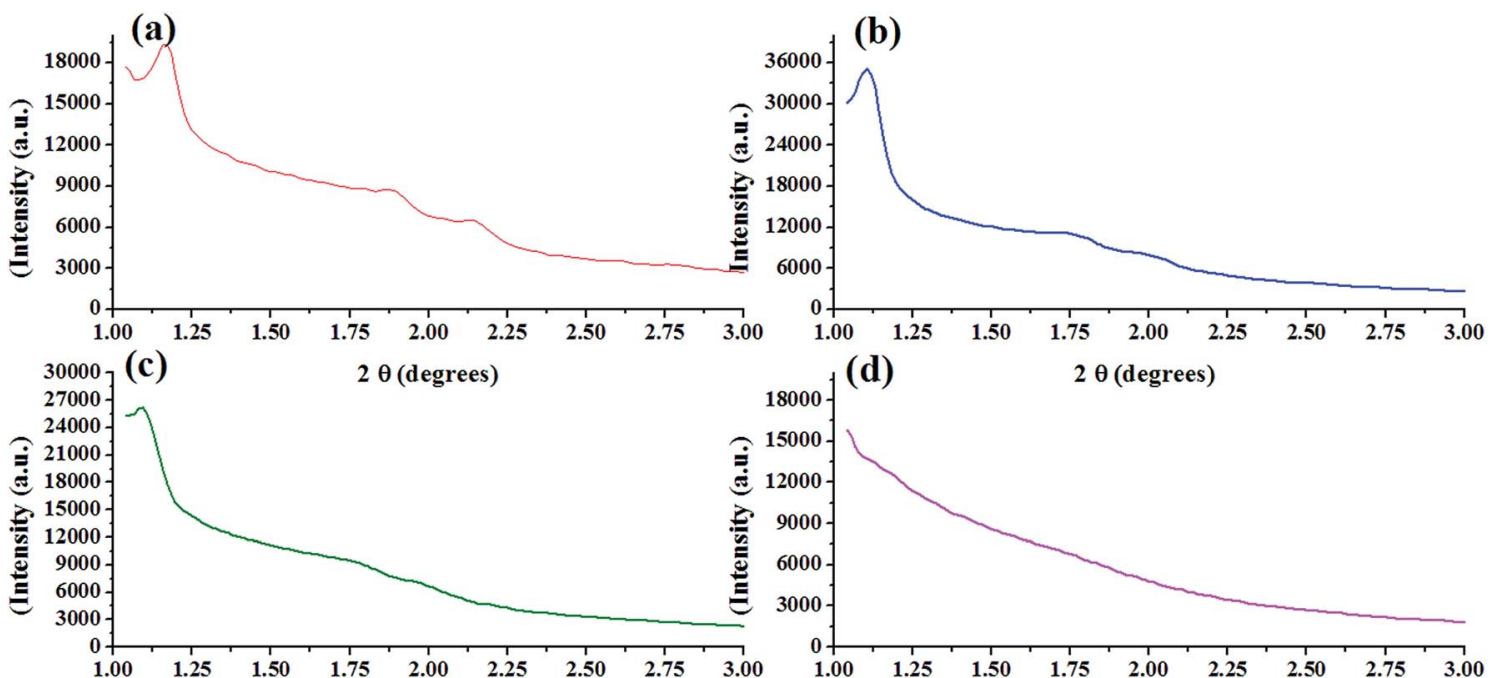

(d)
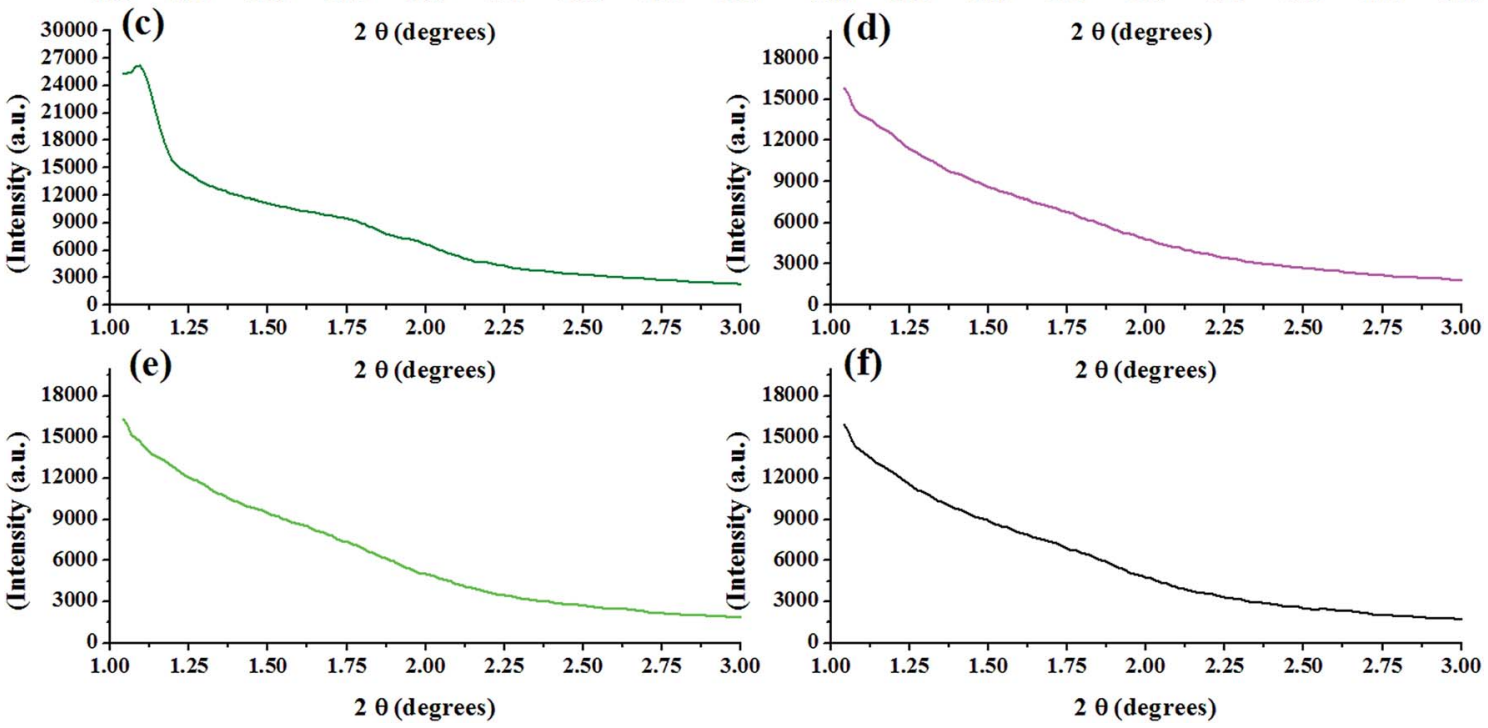

Fig. 5 Small angle powder XRD patterns of calcined (a) KIT-6 and Ti-KIT-6 with Si/Ti ratios; (b) 10, (c) 20, (d) 40, (e) 80, and (f) 100.

\subsection{Catalytic performance of Ti-KIT-6}

The alcoholysis of furfuryl alcohol with $n$-butanol over $0.3 \mathrm{~g}$ of synthesized catalysts was studied at $110{ }^{\circ} \mathrm{C}$ for $5 \mathrm{~h}$ with a feed ratio (furfuryl alcohol : $n$-butanol) $1: 60$ (Scheme 2).

Initially, the butanolysis of FAL was investigated using $80 \mathrm{Ti}-$ KIT-6. The 80Ti-KIT-6 gave $88 \%$ conversion of FAL with $100 \%$ selectivity to BL. As the 80Ti-KIT-6 catalyst showed high activity, the butanolysis of FAL was studied over other synthesized catalysts and their catalytic activity is summarized in Table 2 .

The conversion of FAL was $29 \%$ over 10 Ti-KIT- 6 with $100 \%$ selectivity towards BL. The percentage conversion increased with further increases in titanium content. The 20Ti-KIT-6 and 40Ti-KIT- 6 catalysts showed $42 \%$ and $72 \%$ conversion with $100 \%$ selectivity to BL, respectively. Bracingly, 100Ti-KIT-6 catalyst exhibits $94 \%$ conversion with $100 \%$ selectivity. Productivity is higher than those of other catalysts due to its higher content of active titanium species in the tetracoordinated framework on the inner pore walls of KIT-6. For the sake of comparison, the homogenous catalyst (TTIP) was also evaluated under the same reaction conditions. The TTIP showed moderate conversion of FAL with $100 \%$ selectivity to BL. No conversion of FAL was observed when a separate reaction was performed without catalyst. The high activity of titanosilicate catalysts are due to its active titanium species forming Lewis acid sites, which was confirmed by temperature programmed desorption analyses. The nature of the active sites plays an important role in determining the yield of the BL.

The 100Ti-KIT-6 catalyst was compared with 100Ti-SBA-15 and 100Ti-Si (non-mesostructured silica) catalysts. The catalytic conversion of FAL to BL over 100Ti-SBA-15 was slightly lower as compared to $100 \mathrm{Ti}-\mathrm{KIT}-6$ and $100 \mathrm{Ti}-\mathrm{Si}$ gave a $60 \%$ yield of BL in $5 \mathrm{~h}$. SBA-15 has a 2D hexagonal structure with parallel cylindrical pores whereas KIT-6 has a 3D cubical structure with large interconnecting pores and may provide a better grafting surface for titania. Such a unique 3-D channel network is thought to be able to provide a highly opened porous host with easy and direct access for guest species, thus facilitating

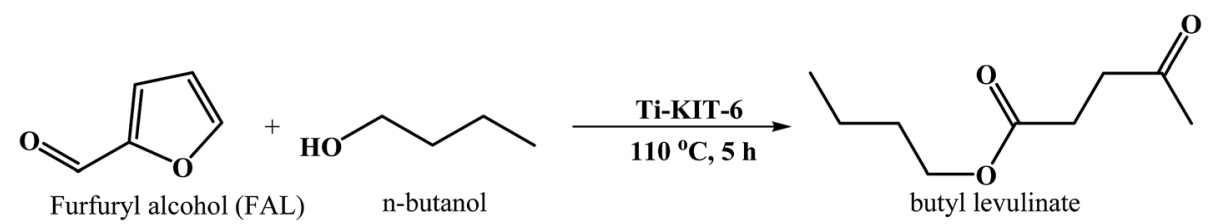

Scheme 2 The synthesis of butyl levulinate from furfuryl alcohol and n-butanol over Ti-KIT-6 catalyst. 
Table 2 Effect of various catalysts on butanolysis reaction ${ }^{a}$

\begin{tabular}{|c|c|c|}
\hline Catalyst & $\begin{array}{l}\text { Conversion }{ }^{b} \\
(\mathrm{~mol} \%)\end{array}$ & $\begin{array}{l}\text { Selectivity }{ }^{c} \\
(\mathrm{~mol} \%)\end{array}$ \\
\hline Nil & - & - \\
\hline KIT-6 & 8 & 100 \\
\hline $\begin{array}{l}\text { Titanium(Iv) } \\
\text { isopropoxide }\end{array}$ & 54 & 100 \\
\hline 10Ti-KIT-6 & 29 & 100 \\
\hline 20Ti-KIT-6 & 42 & 100 \\
\hline 40Ti-KIT-6 & 72 & 100 \\
\hline 80Ti-KIT-6 & 88 & 100 \\
\hline 100Ti-KIT-6 & 94 & 100 \\
\hline 100Ti-SBA-15 & 90 & 100 \\
\hline 100Ti-Si & 60 & 100 \\
\hline $20 \mathrm{wt} \% \mathrm{Al}_{2} \mathrm{O}_{3} / \mathrm{SBA}-15^{d}$ & 100 & 94 \\
\hline $\mathrm{HZSM}-5^{e}$ & 100 & 40 \\
\hline HY-zeolite ${ }^{f}$ & 100 & 3 \\
\hline \multicolumn{3}{|c|}{$\begin{array}{l}{ }^{a} \text { Reaction conditions: feed ratio (furfuryl alcohol : } n \text {-butanol) } 1: 60 \text {, } \\
0.3 \mathrm{~g} \text { catalyst, } 110{ }^{\circ} \mathrm{C}, 5 \mathrm{~h} .{ }^{b} \text { Conversion of furfuryl alcohol determined } \\
\text { by GC. }{ }^{c} \text { Selectivity of butyl levulinate determined by GC. }{ }^{d} \text { Reaction } \\
\text { conditions: feed ratio (furfuryl alcohol : } n \text {-butanol) } 1: 65.5 \text {, } 0.4 \mathrm{~g} \\
\text { catalyst, } 110^{\circ} \mathrm{C}, 6 \mathrm{~h} \cdot{ }^{12} e \text { Reaction conditions: } 110{ }^{\circ} \mathrm{C}, 6 \mathrm{~h} \cdot{ }^{26} f^{f} \text { Reaction } \\
\text { conditions: } 110{ }^{\circ} \mathrm{C}, 12 \mathrm{~h}^{27}\end{array}$} \\
\hline
\end{tabular}

inclusion or diffusion throughout the pore channels with mitigated pore blockage. For the sake of comparison, the activity of the 100Ti-KIT- 6 catalyst was compared with the reported catalysts as shown in Table 2. The catalytic conversion of FAL to BL over HZSM- 5 gave a $40 \%$ yield of BL in $6 \mathrm{~h}$. HY-zeolitecatalysed conversion resulted in a lower yield of BL $(3 \%)$. The $20 \mathrm{wt} \% \quad \mathrm{Al}_{2} \mathrm{O}_{3} / \mathrm{SBA}-15$ also shows excellent performance; however, the formation of other by products such as oligomeric product decreases the quality of the catalyst.

The butanolysis reactions of FAL and $n$-butane were further carried out over 100Ti-KIT-6 to determine the influence of reaction temperature, time, and catalyst amount. The reaction was performed at $70{ }^{\circ} \mathrm{C}$, and the FAL conversion was only $28 \%$ (Fig. 6). When the temperature was increased to $90{ }^{\circ} \mathrm{C}$, the conversion increased drastically to $70 \%$. With a further rise in reaction temperature from $90{ }^{\circ} \mathrm{C}$ to $110{ }^{\circ} \mathrm{C}$, the conversion increased significantly and reached a maximum of $94 \%$. However, an excessive temperature of $130^{\circ} \mathrm{C}$ did not change the productivity compared with that of $110^{\circ} \mathrm{C}$. In all the cases, the selectivity towards (BL) did not change and remained $100 \%$. Thus, $110^{\circ} \mathrm{C}$ was chosen as the optimum reaction temperature for the butanolysis reaction.

Variations of product conversion and selectivity with time were studied at the optimum temperature of $110{ }^{\circ} \mathrm{C}$ and the results are shown in Fig. 7. In the first $1 \mathrm{~h}$, the FAL conversion achieved over 100Ti-KIT- 6 was as high as $80 \%$, suggesting that with the aid of the active titanium species, the reaction proceeded rapidly in a short time. Nevertheless, only $58 \%$ of BL as a major product and $42 \%$ of 2-(butoxymethyl)furan as by product were formed. Upon extending the catalytic test, the $\mathrm{BL}$ selectivity increased gradually but flattened of after $5 \mathrm{~h}$. At the same time, a decrease in the amount of 2-(butoxymethyl)furan was observed. This clearly indicates that the 2-(butoxymethyl)

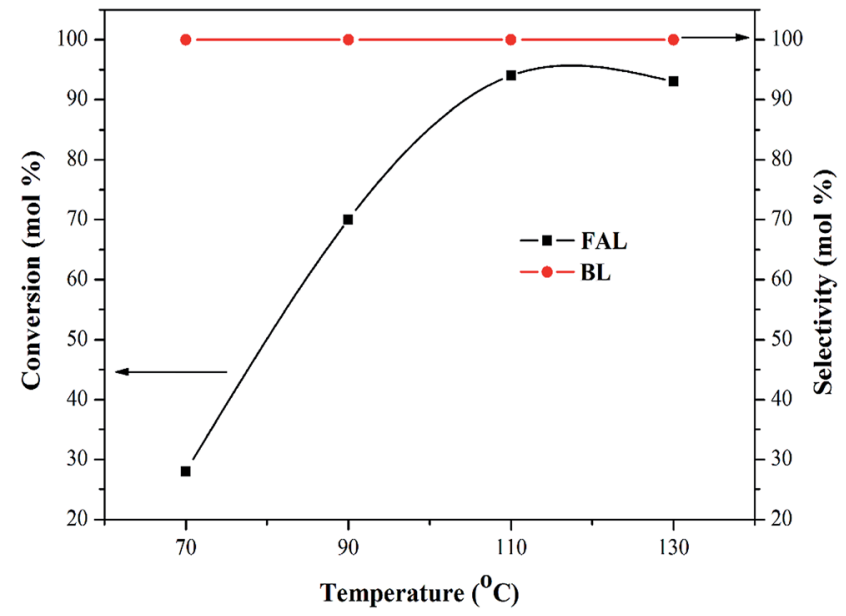

Fig. 6 Butanolysis of FAL at different temperatures over 100Ti-KIT-6. Reaction conditions: feed ratio (furfuryl alcohol: $n$-butanol), $1: 60$; amount of catalyst, $0.3 \mathrm{~g}$; and the reaction time, $5 \mathrm{~h}$.

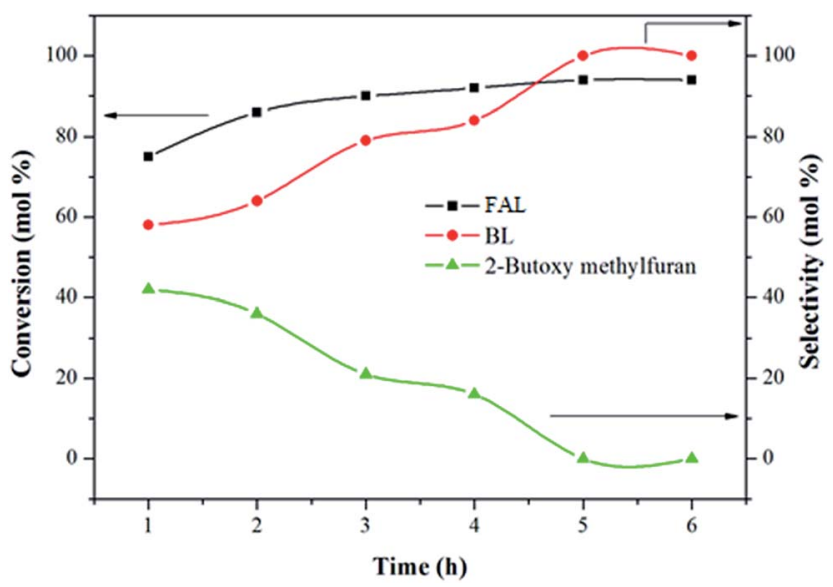

Fig. 7 Butanolysis of FAL at different times over 100Ti-KIT-6. Reaction conditions: feed ratio (furfuryl alcohol: $n$-butanol), $1: 60$; amount of catalyst, $0.3 \mathrm{~g}$; and the reaction temperature, $110^{\circ} \mathrm{C}$.

furan acts as the main intermediate of butanolysis of furfuryl alcohol which further converted to BL as the reaction proceeded. Recently, a similar trend was observed by Roa et al. ${ }^{6}$ over zinc exchanged heteropoly tungstate supported on niobia catalysts.

Table 3 shows the effect of the catalyst amounts on catalytic performance.

It was observed that with increasing amounts of catalyst from $0.1 \mathrm{~g}$ to $0.2 \mathrm{~g}$, the FAL conversion increased from $38 \%$ to $72 \%$. The low amount of catalyst obviously produced low BL due to the less availability of adequate amounts of active sites that react with the intermediate to convert it into BL. With $0.3 \mathrm{~g}$ of catalyst, the conversion apparently increased and achieved $94 \%$ of FAL conversion with $100 \%$ BL selectivity. However, when the catalyst amount increased up to $0.4 \mathrm{~g}$ the percentage conversion remained nearly the same. Since it is not of practical interest to use a large amount of catalyst, thus $0.3 \mathrm{~g}$ of 100Ti-KIT- 6 was 
Table 3 Effect of catalyst amounts on the butanolysis of furfuryl alcohol $^{a}$

\begin{tabular}{lll}
\hline Catalyst amount $(\mathrm{g})$ & Conversion $^{b}(\mathrm{~mol} \%)$ & Selectivity $^{c}(\mathrm{~mol} \%)$ \\
\hline 0.1 & 38 & 100 \\
0.2 & 72 & 100 \\
0.3 & 94 & 100 \\
0.4 & 95 & 100
\end{tabular}

${ }^{a}$ Reaction conditions: feed ratio (furfuryl alcohol : $n$-butanol) $1: 60$, $110{ }^{\circ} \mathrm{C}, 5 \mathrm{~h} .{ }^{b}$ Conversion of furfuryl alcohol determined by GC. ${ }^{c}$ Selectivity of butyl levulinate determined by GC.

fixed as the optimum catalyst amount for the butanolysis of FAL at $110{ }^{\circ} \mathrm{C}$ for $5 \mathrm{~h}$.

\subsection{Heterogeneity test}

In order to determine the leaching of active Ti species from the catalyst, the leaching test was performed by carrying the reaction for $1 \mathrm{~h}$ and then the catalyst was filtered from the reaction mixture. Then it was further continued without catalyst for 4 more hours. No significant increase in conversion of BL was observed. ICP-AES results also agreed that there was insignificant leaching of Ti from catalyst indicating the active Ti species is bound strongly on the inner pore walls of KIT-6.

\subsection{Reusability test}

A crucial aspect of heterogeneous catalyst is its reusability; thus, the reusability of the catalyst was studied taking 100Ti-KIT-6 for butanolysis of FAL. After completion of each catalytic cycle, the catalyst was separated by filtration, washed with acetone, and dried at $100{ }^{\circ} \mathrm{C}$ overnight. Then the catalyst was reused for the next cycle under the same reaction conditions. The results of reusability of the catalyst are shown in Fig. 8.

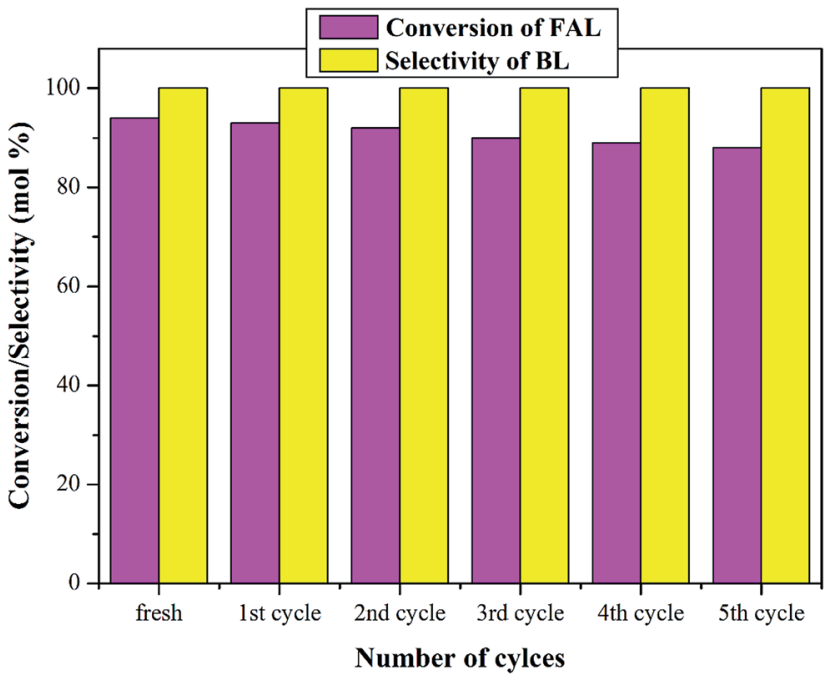

Fig. 8 Reusability of the 100Ti-KIT-6 catalyst. Reaction conditions: feed ratio (furfuryl alcohol: $n$-butanol), $1: 60$; amount of catalyst, $0.3 \mathrm{~g}$; reaction time, $5 \mathrm{~h}$ and the reaction temperature, $110^{\circ} \mathrm{C}$.
The results obtained for the fresh catalyst and spent were almost the same. The catalytic activity was reliable even after fourth cycle. However, the conversion decreased by $6 \%$ in the regenerated catalyst after five cycles. These results clearly show high butanolysis stability of 100Ti-KIT- 6 catalyst. This stability is ascribed to the high amounts of active titanium incorporated exclusively into a framework with tetrahedral coordination.

\section{Conclusions}

Titanium incorporated KIT-6 catalysts were synthesized by a simple sol-gel method, characterized, and its catalytic application was successfully optimized in an alcoholysis reaction with furfuryl alcohol and $n$-butanol. The HR-TEM, PXRD, and $\mathrm{N}_{2}$ sorption analysis of the catalysts confirmed a uniform mesostructure with unique 3D networks of the materials. FT-IR, $\mathrm{NH}_{3}$-TPD, ICP-AES, and ${ }^{29} \mathrm{Si}$ MAS-NMR techniques revealed the excellent stability and acidic properties of the incorporated titanium species in the material framework of KIT-6. Among the catalysts studied, 100Ti-KIT-6 was found to be better than others for an alcoholysis reaction as it gave high yields of butyl levulinate. Moreover, the catalyst showed good recyclability, up to 5 times, and leaching tests clearly showed that these catalysts are outstanding heterogeneous catalysts for the alcoholysis reaction.

\section{Conflicts of interest}

There are no conflicts to declare.

\section{Acknowledgements}

The authors are grateful for the financial support from the University Malaya Research Grant (GC001A-14AET) and Research University Grant (RU004-2017). The authors (R. J. and H. A. A.) extend their appreciation to Deanship of Scientific research, King Saud University for funding through vice Deanship of Research Chairs.

\section{References}

1 S. Xiu and A. Shahbazi, Bio-oil production and upgrading research: A review, Renewable Sustainable Energy Rev., 2012, 16, 4406-4414.

2 M. M. Ambursa, T. H. Ali, H. V. Lee, P. Sudarsanam, S. K. Bhargava and S. B. A. Hamid, Hydrodeoxygenation of dibenzofuran to bicyclic hydrocarbons using bimetallic $\mathrm{Cu}-\mathrm{Ni}$ catalysts supported on metal oxides, Fuel, 2016, 180, 767-776.

3 B. Srinivasa Rao, P. Krishna Kumari, D. Dhana Lakshmi and N. Lingaiah, One pot selective transformation of biomass derived chemicals towards alkyl levulinates over titanium exchanged heteropoly tungstate catalysts, Catal. Today, 2017, DOI: 10.1016/j.cattod.2017.05.040.

4 S. S. Enumula, V. R. B. Gurram, R. R. Chada, D. R. Burri and S. R. R. Kamaraju, Clean synthesis of alkyl levulinates from 
levulinic acid over one pot synthesized $\mathrm{WO}_{3}$-SBA-16 catalyst, J. Mol. Catal. A: Chem., 2017, 426, 30-38.

5 Y.-B. Huang, T. Yang, M.-C. Zhou, H. Pan and Y. Fu, Microwave-assisted alcoholysis of furfural alcohol into alkyl levulinates catalyzed by metal salts, Green Chem., 2016, 18, 1516-1523.

6 B. S. Rao, P. K. Kumari, D. Dhanalakshmi and N. Lingaiah, Selective conversion of furfuryl alcohol into butyl levulinate over zinc exchanged heteropoly tungstate supported on niobia catalysts, Mol. Catal., 2017, 427, 80-86.

7 J. Zhang, S. Wu, B. Li and H. Zhang, Advances in the Catalytic Production of Valuable Levulinic Acid Derivatives, ChemCatChem, 2012, 4, 1230-1237.

8 M. S. Tiwari, A. B. Gawade and G. D. Yadav, Magnetically separable sulfated zirconia as highly active acidic catalysts for selective synthesis of ethyl levulinate from furfuryl alcohol, Green Chem., 2017, 19, 963-976.

9 S. Zhao, G. Xu, J. Chang, C. Chang, J. Bai, S. Fang and Z. Liu, Direct production of levulinate from carbohydrates catalyzed by H-ZSM-5 supported phosphotungstic acid, BioResources, 2015, 10, 2223-2234.

10 M. M. Zainol, N. A. S. Amin and M. Asmadi, Effects of thermal treatment on carbon cryogel preparation for catalytic esterification of levulinic acid to ethyl levulinate, Fuel Process. Technol., 2017, 167, 431-441.

11 L. Peng, X. Gao and K. Chen, Catalytic upgrading of renewable furfuryl alcohol to alkyl levulinates using $\mathrm{AlCl}_{3}$ as a facile, efficient, and reusable catalyst, Fuel, 2015, 160, 123-131.

12 S. S. Enumula, K. S. Koppadi, V. R. Babu Gurram, D. R. Burri and S. R. Rao Kamaraju, Conversion of furfuryl alcohol to alkyl levulinate fuel additives over $\mathrm{Al}_{2} \mathrm{O}_{3} / \mathrm{SBA}-15$ catalyst, Sustainable Energy \& Fuels, 2017, 1, 644-651.

$13 \mathrm{X} . \mathrm{Hu}, \mathrm{R} . \mathrm{J}$. M. Westerhof, L. Wu, D. Dong and C.-Z. Li, Upgrading biomass-derived furans via acid-catalysis/ hydrogenation: the remarkable difference between water and methanol as the solvent, Green Chem., 2015, 17, 219224.

14 D. Song, S. An, Y. Sun and Y. Guo, Efficient conversion of levulinic acid or furfuryl alcohol into alkyl levulinates catalyzed by heteropoly acid and $\mathrm{ZrO}_{2}$ bifunctionalized organosilica nanotubes, J. Catal., 2016, 333, 184-199.

15 X.-F. Liu, H. Li, H. Zhang, H. Pan, S. Huang, K.-L. Yang and S. Yang, Efficient conversion of furfuryl alcohol to ethyl levulinate with sulfonic acid-functionalized MIL-101(Cr), RSC Adv. , 2016, 6, 90232-90238.

16 C. Jo, K. Kim and R. Ryoo, Syntheses of high quality KIT-6 and SBA-15 mesoporous silicas using low-cost water glass, through rapid quenching of silicate structure in acidic solution, Microporous Mesoporous Mater., 2009, 124, 45-51.

17 W. Wang, R. Qi, W. Shan, X. Wang, Q. Jia, J. Zhao, C. Zhang and $\mathrm{H}$. Ru, Synthesis of KIT-6 type mesoporous silicas with tunable pore sizes, wall thickness and particle sizes via the partitioned cooperative self-assembly process, Microporous Mesoporous Mater., 2014, 194, 167-173.

18 L. Xu, C. Wang and J. Guan, Preparation of acid-base bifunctional mesoporous KIT-6 (KIT: Korea Advanced Institute of Science and Technology) and its catalytic performance in Knoevenagel reaction, J. Solid State Chem., 2014, 213, 250-255.

19 J. N. Appaturi and F. Adam, A facile and efficient synthesis of styrene carbonate via cycloaddition of $\mathrm{CO}_{2}$ to styrene oxide over ordered mesoporous MCM-41-Imi/Br catalyst, Appl. Catal., B, 2013, 136-137, 150-159.

20 L. Kumaresan, A. Prabhu, M. Palanichamy and V. Murugesan, Mesoporous Ti-KIT-6 molecular sieves: Their catalytic activity in the epoxidation of cyclohexene, $J$. Taiwan Inst. Chem. Eng., 2010, 41, 670-675.

21 D.-W. Lee, S.-K. Ihm and K.-H. Lee, Mesostructure Control Using a Titania-Coated Silica Nanosphere Framework with Extremely High Thermal Stability, Chem. Mater., 2005, 17, 4461-4467.

22 Y. J. Acosta-Silva, R. Nava, V. Hernández-Morales, S. A. Macías-Sánchez, M. L. Gómez-Herrera and B. Pawelec, Methylene blue photodegradation over titania-decorated SBA-15, Appl. Catal., B, 2011, 110, 108-117.

23 M. Hussain, P. Akhter, G. Saracco and N. Russo, Nanostructured $\mathrm{TiO}_{2} / \mathrm{KIT}-6$ catalysts for improved photocatalytic reduction of $\mathrm{CO}_{2}$ to tunable energy products, Appl. Catal., B, 2015, 170, 53-65.

24 K. J. A. Raj and B. Viswanathan, Effect of surface area, pore volume and particle size of P25 titania on the phase transformation of anatase to rutile, Indian J. Chem., Sect. A: Inorg., Bio-inorg., Phys., Theor. Anal. Chem., 2009, 48, 13781382.

25 M. Selvaraj, Highly active and green mesostructured titanosilicate catalysts synthesized for selective synthesis of benzoquinones, Catal. Sci. Technol., 2014, 4, 2674-2684.

26 P. Demma Carà, R. Ciriminna, N. R. Shiju, G. Rothenberg and M. Pagliaro, Enhanced Heterogeneous Catalytic Conversion of Furfuryl Alcohol into Butyl Levulinate, ChemSusChem, 2014, 7, 835-840.

27 Z. Zhang, K. Dong and Z. Zhao, Efficient Conversion of Furfuryl Alcohol into Alkyl Levulinates Catalyzed by an Organic-Inorganic Hybrid Solid Acid Catalyst, ChemSusChem, 2011, 4, 112-118. 